The following paper was presented at The 9th Workshop on Disfluency in Spontaneous Speech (DiSS 2019) held at ELTE Eötvös Loránd University in Budapest, Hungary on 12-13 September, 2019.

Title: $\quad$ Vowel lengthening - Effect of position, age, and phonological quantity

Author(s): $\quad$ Valéria Krepsz

Abstract: $\quad$ The present research examined the effect of phrase-final lengthening on the spectral structure of vowels in the spontaneous speech of children and adults. Three Hungarian vowel pairs (in quantity pairs) were analyzed in two positions: in the middle of the phrase and at the end of the phrase. The effect of lengthening on the spectral structure of the vowels were already be detected in four-year-olds. However, its extent was strongly correlated with the articulation aspects of the vowels. There was a discrepancy in the tendencies of the lengthening's effect between the two groups of children and the adults, presumably due to different linguistic experience, inaccuracy of articulation, and significant individual differences.

DOI: $\quad$ https://doi.org/10.21862/diss-09-016-krepsz

Citation (JIPA): Krepsz, Valéria. 2019. Vowel lengthening - Effect of position, age, and phonological quantity. In: R. L. Rose \& R. Eklund (eds.), Proceedings of DiSS 2019, The 9th Workshop on Disfluency in Spontaneous Speech, 12-13 September, 2019, Budapest, Hungary, 59-62.

The complete proceedings for DiSS 2019 are available as follows.

ISBN:

978-963-489-063-8

DOI:

https://doi.org/10.21862/diss-09

DiSS 2019 was sponsored by The Faculty of Humanities, ELTE Eötvös Loránd University and the International Speech Communication Association (ISCA).
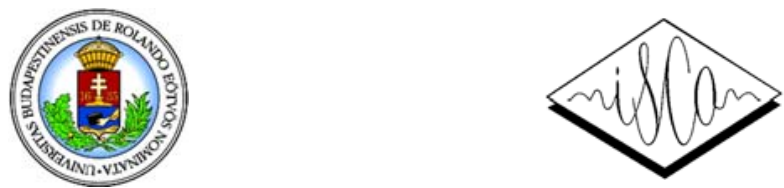


\title{
Vowel lengthening - Effect of position, age, and phonological quantity
}

\author{
Valéria Krepsz \\ Research Institute for Linguistics, Hungarian Academy of Sciences, Budapest, Hungary
}

\begin{abstract}
The present research examined the effect of phrasefinal lengthening on the spectral structure of vowels in the spontaneous speech of children and adults. Three Hungarian vowel pairs (in quantity pairs) were analyzed in two positions: in the middle of the phrase and at the end of the phrase. The effect of lengthening on the spectral structure of the vowels were already be detected in four-year-olds. However, its extent was strongly correlated with the articulation aspects of the vowels. There was a discrepancy in the tendencies of the lengthening's effect between the two groups of children and the adults, presumably due to different linguistic experience, inaccuracy of articulation, and significant individual differences.
\end{abstract}

\section{Introduction}

Examination of prosodic features of speech is greatly encumbered by the fact that these elements are multidimensional, and also contain several acoustic parameters that overlap in terms of function and appearance (Cutler et al., 1997). In addition to the meaning-modifying and meaning-carrier functions of these prosodic elements, they provide a dividing function in the utterances. Although these factors are present not only at the end of utterances, earlier research findings suggest that combinations of these individual elements occur more frequently with a boundary marker function. Previous studies mostly agree on the list of prosodic elements that can function as boundary markers, however, it is also important to emphasize that realization can vary depending on a number of factors (Wightman et al., 1992). Some of the main boundary markers are (silent) pauses, changes in fundamental frequency, changes of voice quality, and phrase-final lengthening.

The current research focuses on the phenomenon of phrase-final lengthening (PhFL) in the spontaneous speech of Hungarian monolingual children and adults. The results of previous studies suggested that phrase-final lengthening can be observed in English-speaking children by the age of 2 , and confirmed that PhFL as a learnt prosodic feature has a close connection with the quality and amount of linguistic experience (Snow, 1994). Other studies suggested that the occurrence of PhFL was still not systematic in English-speaking children at the age of 8 , and the individual differences were substantial (Dankovičová et al., 2004). Krepsz et al. (in press) have confirmed the appearance of vowel elongation in the last syllable in pre-pausal position already at the age of 3 . The results showed a significant difference in the duration of the 4 most common Hungarian vowels depending on the quality and position (initial, medial and final occurrence in the phrase) of the vowels. The duration of vowels were gradually decreasing with age, independently from the other examined features.

The articulation of vowels at the segmental level is basically described with three features: the horizontal and vertical position of the tongue (for the latter, some authors use the term closeness or openness) relative to its resting position, and lip activity. Considering the differences in quality and duration, we can assume that there are only 9 vowel qualities in Hungarian, which (illustrated by the long member of the phonological pairs) are: /i: y: u: e: ø: o: $\varepsilon$ a: $\mathfrak{p} /$. However, long vowels differ from their short pairs more or less in their quality, the difference being strongly dependent on the tongue's vertical position (cf. Kassai, 1998; Gósy, 2004). This phenomenon can be grasped well within the framework of the H\&H theory (Lindblom, 1963) that raises the question of whether the structure of hypoand hyperarticulation vowels are different. Therefore the question of the current research whether the target configurations of Hungarian short and long vowels are different, and if so, whether the short vowels can be described as over-configured gestures of their long pairs (for a detailed description of the problem in Hungarian, see the following study). Mády's (2008) research, based on the examination of two speakers with the use of electromagnetic articulographs, found that /o/ and /o:/ vowels differ from each other in their height (openness), there was a clear difference between the articulation of the vowels $/ \varepsilon /$ and /e:/, especially in terms of their height (openness).

Based on the previous results, the aim of the present study was to investigate whether there was a difference in the formant structure of short and long vowel pairs in different positions (with lengthening in phrase-final position, without lengthening in 
phrase-medial position). According to our hypotheses: i) the lengthening effect on the formant structure of the short vowels will be less pronounced than on that of the long ones, ii) the effect of lengthening will be different in the realization of mid and open vowels, iii) differences will be smaller in children than in adults.

\section{Subjects, material and method Participants}

Data were analyzed from 20 monolingual, Hungarian speaking girls aged $4(n=10)$ and $6(n=10)$ from the GABI database (Bóna et al., 2014). The participants had, as indicated by their parents, typical cognitive skills, and no speech, language or hearing problems. The socio-economic status of the participants was not controlled; however, all of the children were recruited from public kindergartens in Hungary. The children's data were compared to sound samples of young women $(n=10$; aged between 25 and 35 years), the samples having been selected from the BEA database (Gósy, 2013).

\section{Method and material}

In this paper, we investigate the spontaneous speech of subjects from all three age groups. All speakers talked about their family and free time activities; children also talked about the rules of their favorite games, while adults talked about their studies and jobs. The total length of the recorded material analyzed here was 143 minutes 34 seconds, 8 minutes 45 seconds of spontaneous speech per adult and 3 minutes 22 seconds per child (on average).

The choice of the basic unit of annotation can influence the examined values, such as phrase-final lengthening. However, speech production of fourand six-year-olds is characterized by short speech periods and long pauses, even though there are great individual differences. Therefore we considered speech units from pause to pause as the basic unit of this segmentation. In this way, the data of speakers of different ages could be compared. The annotation of speech units and vowels was carried out manually under Praat (Boersma \& Weenink, 2018). The segmentation of the vowels was based on their second formants, supported by visual analysis of their respective wide-band spectrograms and waveforms.

To control for factors affecting vowel duration, the following criteria were used for selecting vowels for analysis: a) Only allophones of /p/, /a:/, / $\varepsilon /$, /e:/, $/ 0 /$, and /o:/ were analyzed to control for vowel quality, b) Vowels were chosen from two positions within the utterances: the absolute end of the phrase (before the break, phrase-final position) and from the middle of the words (phrase-medial position), c) Vowels were chosen only from closed syllables, and d) from unstressed positions.

The data set included a total of 4094 vowels, for which duration as well as first and second formants were analyzed. In addition, the following formula was used to examine the effect of elongation of vowels at phrase-final position: the duration of the speech unit was divided by the number of syllables (until the examined syllable, which was excluded), which gave the articulation rate in syllable per second. Then the duration of the last syllable was divided by the above mentioned articulation rate. This number showed the ratio of the (phrase-final) lengthening (compared to the phrase-medial position).

For statistical analyses, we used the R program (linear mixed model; Venables, 2018). The independent variables were 'age' with three levels (4- and 6-year-olds, and adult), 'position' with two levels (phrase-final, $\mathrm{PhF}$ and phrase-medial, $\mathrm{PhM}$ ) and 'vowel quality' with six levels, 'vowel quantity' with two levels (short and long vowels). The person of the speaker was the random factor. The dependent variables were duration, the F1 and the F2 value of the vowels and 'Euclidean distance'.

\section{Results}

The phenomenon of PhFL was detectable irrespective of the age of the speakers and the quality of the vowels. In the case of short vowels, the ratio of lengthening was higher ( 0.012 on average), and it was lower ( 0.008 on average) in the case of long vowels (Figures 1 and 2). There was a gradual decrease with the increase in the speaker's age: the greatest lengthening was found in four-year-olds ( 0.013 on average), then in six-year-olds ( 0.011 on average) and the smallest in the group of adult speakers ( 0.009 on average).

The statistical analysis showed significant difference in the duration of the vowels depending on the position $[F(1,4094)=26.142 ; p=0.001]$ and age $[F(1,4094)=14.826 ; p=0.019]$ : the duration of vowels shortened with age, however, the pairwise

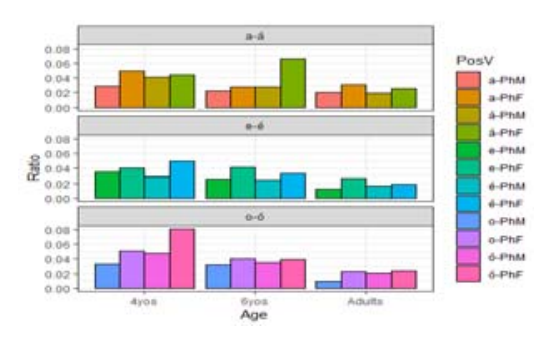

Figure 1. The extent of lengthening (ratios) depending on the speaker's age and the quality of the vowels. 

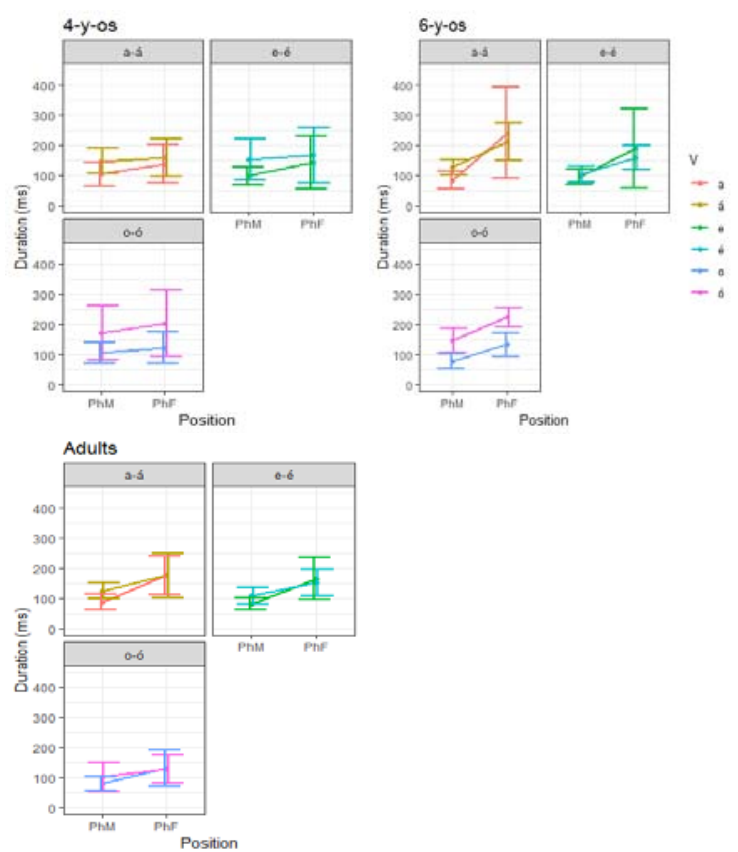

Figure 2. The duration of vowels by the age of the speaker and the quality and quantity of the vowels.

comparison proved difference only between children and adults.

The quality of the vowel and the interaction of the factors did not prove to be decisive in vowel lengthening.

Formant values were analyzed depending on position, vowel quality and the speaker's age. According to the statistical analysis, there was significant difference in $F 1$ values by age $[F(2,4094)=10.546 ; p=0.022]$, and vowel quality $[F(5,4094)=33.317 ; p=0.014]$. Although position did not prove to be a decisive factor in itself, tendentious differences regarding vowel quality were
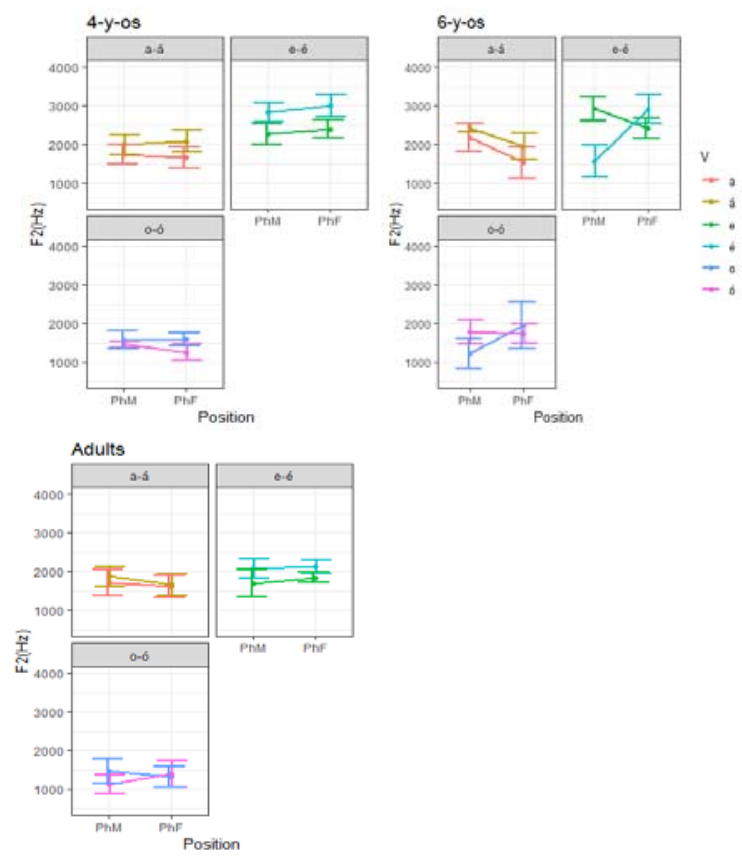

Figure 4. F2 values depending on the age of the speakers and the quality and quantity of the vowels.
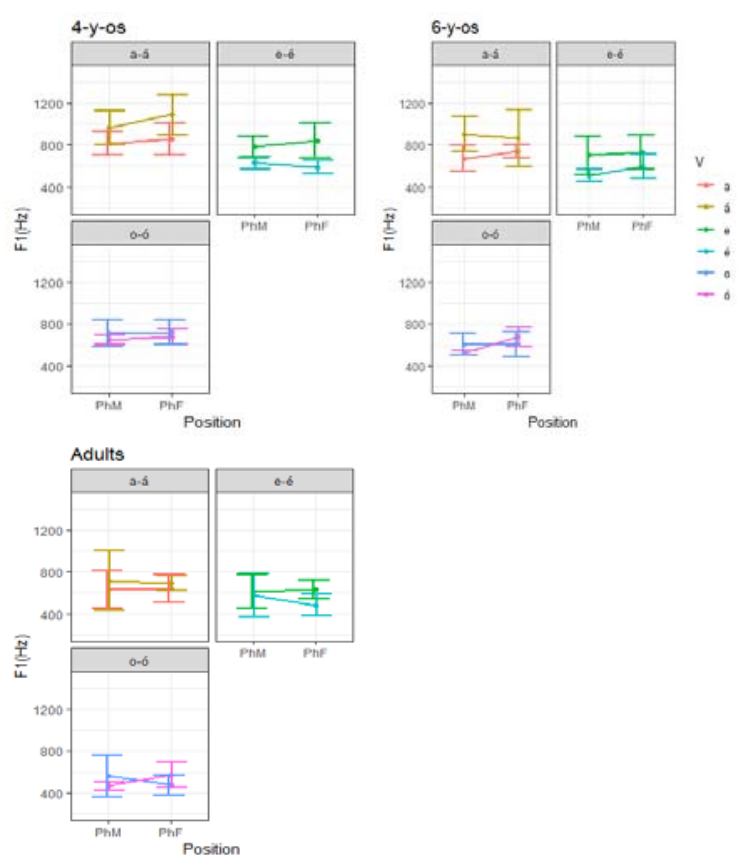

Figure 3. F1 values depending on the age of the speakers and the quality and quantity of the vowels.

observed in the development of F1 values. As Figure 3 shows, the tendencies of $/ \mathrm{p} /$ and $/ \varepsilon /$ vowels were clear: in the case of phrase-final position, the value of F1 was higher.

The realization of /a:/ and /e:/ vowels was determined by the age of the speakers: for the vowel /a:/, difference between the phrase-final and phrasemedial positions was found only in four-year-olds, where the lengthened realization had higher F1 values. For the vowel /e:/, higher F1 values were found at the phrase-medial position in the group of 4-year-olds and adults; and at the phrase-final position in the group of 6-year-olds. There was only a slight difference between the two positions for $/ \mathrm{o} /$; while for $/ o: /$, although the differences were small, lower mean F1 values were measured in the phrasefinal position in all three age groups.

F2 values showed no significant difference by position either: values of F2 showed diversity by the quality and quantity of vowels and by age. Similarly to the first formant, there was a significant difference in the second formant by the quality of the vowels $[F(5,4094)=44.434 ; p=0.007]$ and the speaker's age $[F(2,4094)=9.842 ; p=0.030]$, and the interaction of the position and vowel quality $[F(5,4094)=4.438 ; p=0.034]$, as well as the triple interaction of position, vowel quality and age were also significant $[F(21,4094)=9.931 ; p=0.015]$.

In the case of $/ \mathrm{p} /$ and $/ \mathrm{a}: /$ the tendency was clear: the average of F2 decreased at the phrase-final position in all three age groups (Figure 4). The difference according to position was minimal for $/ \varepsilon /$ and /e:/, the average difference was only $15 \mathrm{~Hz}$. In the case of /o o:/ pairs the trend was different 
depending on age: in four-year-olds and adults we measured higher F2 values at the phrase-final position, while the tendency was the opposite in sixyear-olds. In the case of /o:/, there was a decreasing tendency for children and an increasing tendency for adults.

The Euclidean distance from the center of the vowel area was not influenced by the position.

\section{Conclusions}

The present study analyzed the effect of the position $(\mathrm{PhF}$ or $\mathrm{PhM})$ on the duration and formant structure (F1 and F2) of 3 Hungarian quantity vowel pairs in the spontaneous speech of children and adults. The phenomenon of PhFL was detectable independently from the other analyzed factors and the rate of the lengthening was higher in children than in adults. Although there was no significant difference in either F1 or F2 values according to position, (limited) conclusions about the changes in vowel quality can be drawn. In addition, it is important to emphasize that from the change of vowel formant structure, we can only draw conclusions about the articulation of vowels indirectly and with constraints. The lengthening was most determinative in the case of $/ \mathrm{w} /$ and $/ \mathrm{a}: /$, it is likely that the pronunciation of both vowels became more open and the position of the tongue shifted backwards. In addition, the change of the first formant of the $/ \varepsilon /$ vowel may indicate that it has also been more openly pronounced. Although the quantity of the vowel as a factor was also not determinative for either of the two formant values, the change in the formant values of the short vowels was less variable with regard to the speakers' age. The variance of the formants was greater in the case of higher heights, while in the case of lower heights, greater stability and lesser age sensitivity were observed. Age proved to be a determinative factor for most of the analyzed features. There was a discrepancy in the tendencies of the lengthening between the two groups of children, presumably due to different linguistic experience, inaccuracy of articulation, and significant individual differences. In addition, it is important to emphasize that the imitation of tongue movements is difficult as they mostly take place inside the mouth cavity. Therefore, the acoustic differences resulting from tongue movement appeared and become similar to adults' at a late station of the language acquisition.

\section{Acknowledgements}

This research was supported by the Hungarian National Research, Development and Innovation Office of Hungary, project No. NKFIH-K-120234.

\section{References}

Boersma, P. \& D. Weenink. 2018. Praat: Doing phonetics by computer (version 6.0.37). http://www.praat.org/ (accessed 14 November 2018)

Bóna, J., A. Imre, A. Markó, V. Váradi \& M. Gósy. 2014. GABI - Gyermeknyelvi beszédAdatBázis és Információtár [GABI - Children's Speech and Informational Database]. Beszédkutatás 22: 246-251.

Cutler, A., D. Dahan \& W. Van Donselaar. 1997. Prosody in the comprehension of spoken language: A literature review. Language and speech 40(2): 141-201. https://doi.org/10.1177/002383099704000203

Dankovičová, J., K. Pigott, B. Wells \& S. Peppé. 2004. Temporal markers of prosodic boundaries in children's speech production. Journal of the International Phonetic Associaion 34(1), 17-36. https://doi.org/10.1017/S0025100304001525

Gósy, M. 2004. Fonetika, a beszéd tudománya. Budapest: Osiris.

Gósy, M. 2013. BEA - A multifunctional Hungarian spoken language database. Phonetician n. 105-106: 50-61.

Kassai, I. 1998. Fonetika. Budapest: Nemzeti Tankönyvkiadó.

Krepsz, V., V. Horváth, M. Gósy \& A. Huszár. In press. Magánhangzók temporális mintázata az anyanyelvelsajátításban [Temporal pattern of vowels during first language acquisition].

Lindblom, B. 1963. Spectrographic Study of Vowel Reduction. The Journal of the Acoustical Society of America 35(11): 1773-1781. https://doi.org/10.1121/1.1918816

Mády, K. 2008. Magyar magánhangzók vizsgálata elektromágneses artikulográffal normál és gyors beszédben [Analysis of Hungarian vowels with electromagnetic articulograph in normal and fast speech]. Beszédkutatás 16: 52-66.

Snow, D. 1994. Phrase-Final Syllable Lengthening and Intonation in Early Child Speech. Journal of Speech Language and Hearing Research 37(4): 831-840. https://doi.org/10.1044/jshr.3704.831

Venables, W. N. \& D. M. Smith. R Core Team. 2018. An Introduction to $R-$ Notes on $R$ : a programming environment for data analysis and graphics (version 3.5.0). https://cran.r-project.org/ (accessed 4 October 2018).

Wightman, C. W., S. Shattuck-Hufnagel, M. Ostendorf \& P. J. Price. 1992. Segmental durations in the vicinity of prosodic phrase boundaries. Journal of the Acoustical Society of America vol. 91(3): 1707-1717. https://doi.org/10.1121/1.402450 